\title{
Nonspecific aortoarteritis with lesion of the pulmonary artery left branch (Takayasu's disease)
}

\author{
Saule Abseitova ${ }^{1}$, Elmira Chuvakova $^{2}$, Timur Sarsengaliyev $^{2}$, Natalia \\ Krivoruchko $^{3}$, Bagdad Abdizhami ${ }^{4}$, Akmaral Moldazhanova ${ }^{4}$
}

${ }^{1}$ Outpatient Consulting Center, National Scientific Medical Center, Astana, Republic of Kazakhstan

${ }^{2}$ Radiation Diagnostics Department, National Scientific Medical Center, Astana, Republic of Kazakhstan

${ }^{3}$ No 4 Therapy Department, National Scientific Medical Center, Astana, Republic of Kazakhstan

${ }^{4}$ Cardiology Department, National Scientific Medical Center, Astana, Republic of Kazakhstan

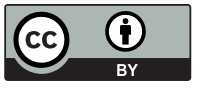

This work is licensed under a

Creative Commons Attribution 4.0 International License

Received: 2018-01-14

Accepted: 2018-03-18

UDC: 616.1

J Clin Med Kaz 2018; 1(47):44-48

Correspondence Author: Saule Abseitova, MD, associate professor, highest category cardiologist, National Scientific Medical Center. 42, Abylay Khan avenue, Astana, 010009, Kazakhstan. Tel.:+77017336232 E-mail: s.abseitova@mail.ru

\section{Abstract}

The goal is to describe a clinical case of a patient with nonspecific aortoarteritis. A special feature of this case is the lesion of the left branch of the pulmonary artery, the progression of the disease with the development of pulmonary hypertension and dilatation of the right heart, combined defeat of the descending thoracic aorta and brachiocephalic arteries. The issues of long-term course of the disease and the difficulties of diagnosis are discussed, in order to help practitioners of different profiles to increase the detectability and early diagnosis of this disease.

Keywords: nonspecific aortoarteritis, pulmonary artery, pulmonary hypertension

\section{ӨКПЕ АРТЕРИЯСЫНЫҢ СОЛ ЖАҚ ТАРМАҒЫНЫҢ ЗАҚЫМДАНУЫМЕН ӨТЕТІН АРНАЙЫ ЕМЕС АОРТОАРТЕРИИТ} (ТАКАЯСУ АУРУЫ)

Абсеитова С.Р. ${ }^{1}$, Чувакова Э.К. ${ }^{2}$, Сарсенгалиев Т.И. ${ }^{2}$, Криворучко Н.А. ${ }^{3}$, Абдижами Б.А. ${ }^{4}$, Молдажанова А.М. ${ }^{2}$

${ }^{1}$ Амбулаторлық консультациялық орталық,Ұлттық ғылыми медициналық орталық, Астана, Қазақстан Республикасы

${ }^{2}$ Сәулелік диагностика бөлімі, Ұлттық ғылыми медициналық орталық, Астана, Қазақстан Республикасы

${ }^{3} № 4$ терапия бөлімшесі, Ұлттық ғылыми медициналық орталық, Астана, Қазақстан Республикасы

${ }^{4}$ Кардиология бөлімшесі, Ұлттық ғылыми медициналық орталық, Астана, Қазақстан Республикасы

\section{ТҰЖЫРЫМДАМА}

Бұл мақалада арнайы емес аортоартериті бар науқастың клиникалық жағдайының сипаттамасы келтірілген. Бұл жағдайдың ерекшелігі - өкпе артериясының сол жақ тармағының закымдануы болып келеді, ауру өкпе гипертензиясының дамуымен, жүректің он жак жүрекшесінің кеңейуімен және кеуде аортасының, брахиоцефалдық артериялардың закымдалуымен бірге жүретін түрі. Аурудың ұзақтығы мен диагноздың қиындықтары туралы мәселелер талқыланады. Әр түрлі профильді мамандарға осы ауруды анықтауда және ерте диагностикалауды жақсартуға көмектесу мақсатында жазылған клиникалык жағдай.

Маңызды сөздер: арнайы емес аортоартериит, өкпе артериясы, өкпе гипертензиясы 


\section{НЕСПЕЦИФИЧЕСКИЙ АОРТОАРТЕРИИТ С ПОРАЖЕНИЕМ ЛЕВОЙ ВЕТВИ ЛЕГОЧНОЙ АРТЕРИИ (БОЛЕЗНЬ}

\section{ТАКАЯСУ)}

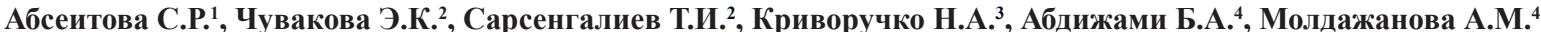

${ }^{1}$ Амбулаторно-консультационный центр, Национальный научный медицинский центр, Астана, Республика Казахстан

${ }^{2}$ Отдел лучевой диагностики, Национальный научный медицинский центр, Астана, Республика Казахстан

${ }^{3}$ Отделение терапии №4, Национальный научный медицинский центр, Астана, Республика Казахстан

${ }^{4}$ Отделение кардиологии, Национальный научный медицинский центр, Астана, Республика Казахстан

\section{PEЗЮME}

Приводится описание клинического случая больной неспецифическим аортоартериитом. Особенностью данного случая являются поражение левой ветви легочной артерии, прогрессирование заболевания с развитием легочной гипертензии и дилатацией правых отделов сердца, сочетанное поражение нисходящего отдела грудной аорты и брахиоцефальных артерий, в помощь практикующим врачам различного профиля для повышения выявляемости и ранней диагностики данного заболевания.

Ключевые слова: неспецифический аортоартериит, легочная артерия, легочная гипертензия

\section{Введение}

Неспецифическийаортоартериит-этогранулематозное воспаление аорты и ее основных ветвей с развитием стеноза или окклюзии поражённых сосудов и вторичной ишемией органов и тканей. Заболевание впервые описано японским офтальмологом Микито Такаясу в 1908 году. Поражает чаще молодых людей, в основном женщин. Заболеваемость составляет 1,2-3,6 случаев на 1.000.000 населения. Средний возраст заболевших на разных континентах различается в Европе 40 лет, Индии - 25, Япония 30 лет. Также известен как «болезнь отсутствия пульса» из-за частых случаев пропадания пульса в верхних конечностях. Чаще всего не удается установить причину, есть данные о повышенной частоте ряда антигенов гистосовместимости у заболевших в различных популяциях, также предполагается связь с туберкулезом и стрептококковыми инфекциями [1].

\section{Описание клинического случая}

Больная Е., 40 лет, с жалобами на постоянные боли в спине, левой половине грудной клетки, одышку при физической нагрузке, головокружение, нарастающую слабость, снижение трудоспособности, угнетена неопределенностью и тяжестью своего состояния.

Анамнез жизни: Менструации с 13 лет, без нарушений. Прием гормональных контрацептивов отрицает. 3 беременности, 3 родов, течение первых двух беременностей без особенностей.

Анамнез заболевания: до 36 лет считала себя здоровым человеком. Со слов заболела через 6 месяцев после родов, когда впервые летом 2013 года появился «ком» между лопатками, самостоятельно массажировала, пользовалась обезболивающими мазями с кратковременным эффектом. В течение 2014, 2015 года неоднократно обследовалась и лечилась у терапевта, невролога. Без эффекта от проведенной терапии.

В это же время больная отмечает присоединение болей в левой половине грудной клетки без четкой локализации, ухудшение самочувствия, слабость, появление пульсации яремных вен, нарушения сна.

В 2016 году с подозрением на левостороннюю нижнедолевую плевропневмонию направлена на стационарное лечение, при проведении рентгенологического исследования выявлены фиброзные «поствоспалительные» изменения левого легкого, в анализе крови - тромбоцитоз, выписана без улучшения самочувствия. В последующем самостоятельно обратилась и наблюдалась пульмонологом, который в связи с отсутствием положительной динамики общего состояния в апреле 2017 года направил на эхокардиографическое (ЭхоКГ) исследование. Заключение: Структурной патологии клапанного аппарата сердца не выявлено, полостные размеры сердца в пределах нормы. Фракция выброса левого желудочка (ФВ ЛЖ) - 62\%.
Митральная регургитация и трикуспидальная регургитация І степени. РСДЛА 27 мм. рт. ст.

В октябре 2017 года с целью исключения образования средостения и туберкулеза легких направлена на компьютерную томографию (КТ) и консультацию торакального хирурга. Результаты КТ исследования без контрастирования: Легочный рисунок прослеживается по всем легочным полям, несколько деформирован за счет пневмосклероза, диффузно по всем полям отмечается некоторое повышение плотности легочной ткани по типу «матового стекла». Стенки бронхов, несколько уплотнены, просветы не расширены. Корни малоструктурные, проходимость трахеи и главных бронхов не нарушена. Сердце несколько расширено в поперечнике. Лимфоузлы не увеличены. Костная структура сохранена. Заключение: Картина хронического бронхита с признаками пневмонита, диффузного пневмосклероза.

При настоящем обращении в клинику больная предъявляет жалобы на общее плохое самочувствие, боли в спине в межлопаточном пространстве, в левой половине грудной клетки, мигрирующего характера (периодически усиливаются), одышку возникающую при физической нагрузке, головокружение, общую слабость, слабость в руках, похолодание кистей. При физикальном обследовании пониженного питания, астеничного телосложения, кожные покровы с бледно серым оттенком. Грудная клетка обычной формы, обе половины равномерно участвуют в акте дыхания. Границы относительной тупости сердца: правая смещена на 0,5 см вправо от правого края грудины, верхняя - на уровне III межреберья по срединно-ключичной линии слева, левая - на 0,5 см внутрь от срединно-ключичной линии. Тоны сердца приглушены, выслушивается грубый систолический шум над проекцией легочной артерии, и в точке Боткина-Эрба с проведением в левую надключичную область, ритм сердца правильный. Пульс 85 ударов в минуту. Артериальное давление (АД) на левой руке 85/60 мм. рт. ст., АД на правой руке 70/60 мм. рт. ст., слабого наполнения и напряжения. АД на нижних конечностях 120/80 мм. рт. ст.

При проведении ЭхоКГ исследования (17.11.17) выявлена: Дилатация правых отделов сердца. Дилатация фиброзного кольца трикуспидального клапана. Трикуспидальная недостаточность III степени. Вегетации на клапанах сердца не выявлено. Выраженная легочная гипертензия (РСДЛА 75-80 мм. рт. ст.). Глобальная систолическая функция ЛЖ удовлетворительная ФВ ЛЖ $62 \%$.

По данным КТ грудного сегмента с в/в болюсным контрастированием (22.11.17): диаметр ствола легочной артерии (ЛА) до 26 мм, правой ветви до 13 мм, в левой ветви выявлено сужение просвета до 5 мм протяженностью до 12 мм (Рисунок 1). 

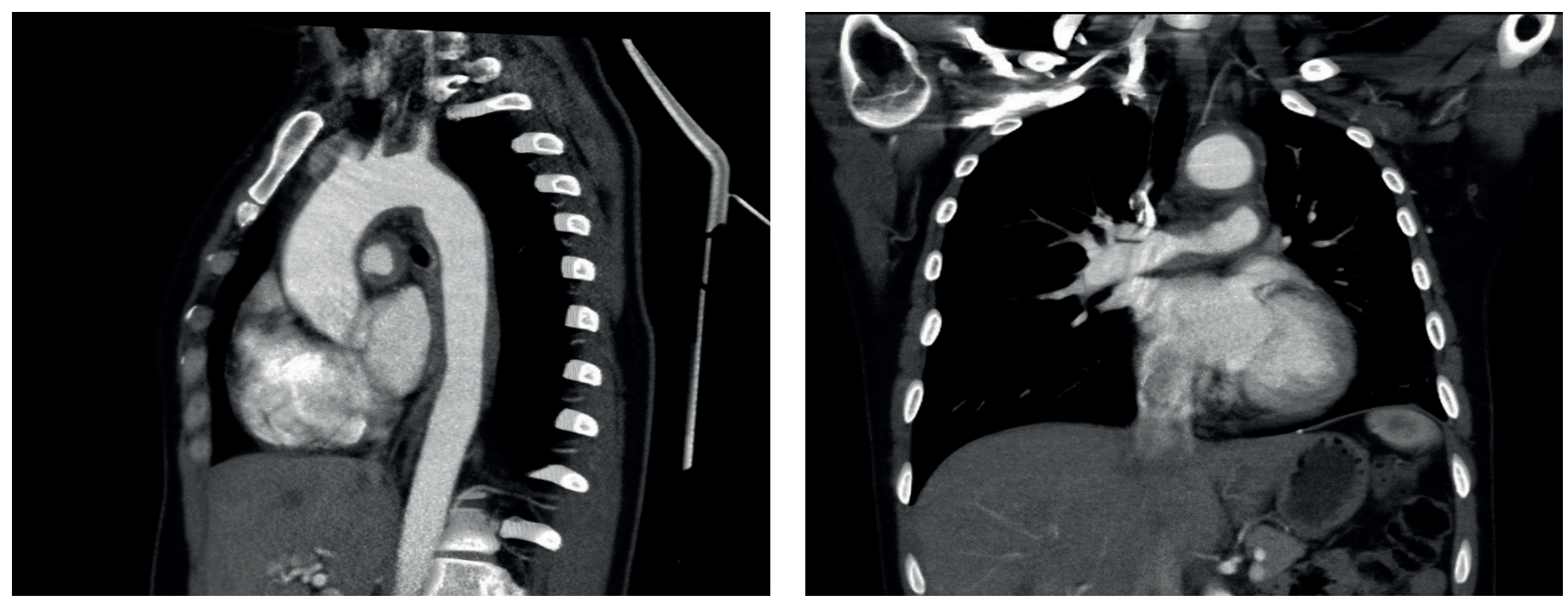

Рисунок 1 - КТ-ангиография больной Е. с неспецифическим аортоартериитом. Определяется протяженное утолщение стенки нисходящей грудной аорты и левой ветви легочной артерии с признаками стенозирования просвета.

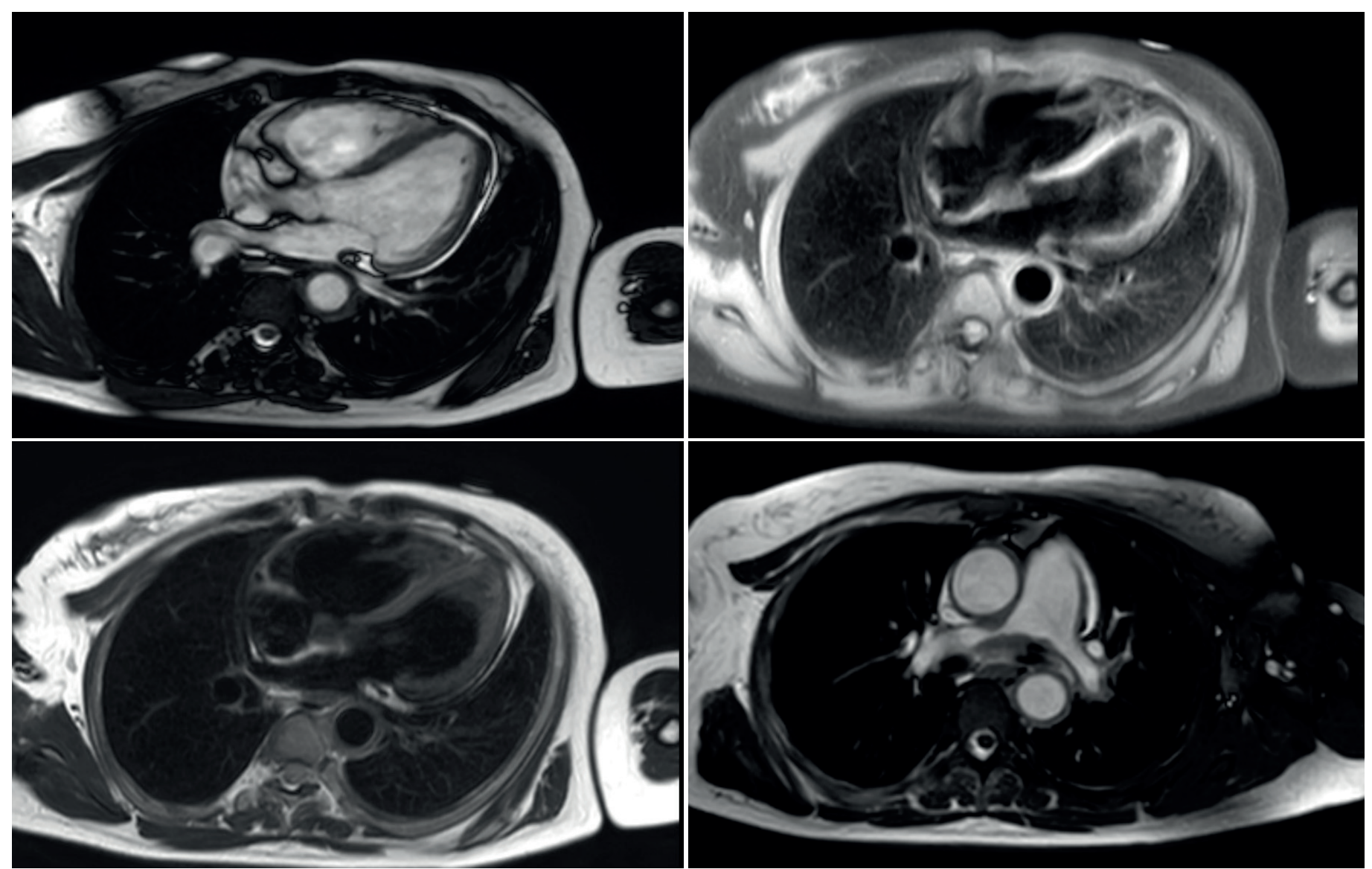

Рисунок 2 - МРТ исследование больной Е. с неспецифическим аортоартериитом.

При проведении МРТ сердца и магистральных сосудов дифференцируется циркулярное утолщение стенки нисходящей грудной аорты и левой ветви легочной артерии с признаками стенозирования просвета.

Для подтверждения неспецифического аортоартериита проведена магнитно-резонансная томография (МРТ) органов средостения с контрастированием. При МР исследовании: утолщение стенок нисходящей грудной аорты и левой ветви легочной артерии соответствующее аортоартерииту (Рисунок 2). Дилатация ствола легочной артерии с признаками стенозирования ветви ЛА. Глобальная сократительная способность миокарда левого желудочка удовлетворительная ФВ 51 - 60\%. Снижение ударного объема 39,2 - 40,8 мл/мин, сердечного выброса 4,0 - 4,2 л/ мин, сердечного индекса 2,3 - 2,4 мл/мин. Дилатация камер сердца.

При ультразвуковой допплерографии (УЗДГ) брахиоцефального ствола: Стенки общей сонной артерии (ОСА) диффузно утолщены, признаки аортоартериита. Гемодинамически незначимый стеноз ОСА по диаметру справа - 52\%, слева - 53\%.

Показатели исследования крови: повышение высокочувствительного С-реактивного белка (вч-СРБ) до 65 мг/л, лейкоцитов до 10.73х109/л, нейтрофилов до 7.60х109/л, 
тромбоцитов до 586х109/л, снижение гемоглобина (HGB) 97.00 г/л; Повышенный фибриноген до 8.26 г/л и d-димеры до 1.38 мкг/мл.

На основании вышеизложенных анамнестических, клинических данных и результатов проведенного исследования поставлен диагноз: Неспецифический аортоартериит с преимущественным поражением левой ветви легочной артерии, нисходящего отдела грудной аорты, брахиоцефальных артерий. IV тип с сочетанием I, II типов. Активность II степени, подострое течение. Вторичная легочная гипертензия III степени. CH ФК II (NYHA). Назначено лечение с учетом активности аутоиммунного процесса глюкокортикостероиды, иммунносупрессивная терапия, антикоагулянты, сосудистые препараты (болюсное введение преднизолон в/в 500 мг, затем таблетированные формы преднизолона 20 мг/сут, иммунносупрессивная терапия - лефно 20 мг/сут на 2 месяца, с последующей коррекцией дозы и сроков приема, эноксапарин п/к, ацетилсалициловая кислота 100 мг/сут, мельдоний 1,0 в/в, затем внутрь 1000 мг/сут).

\section{Обсуждение}

Различают следующие анатомические варианты неспецифического аортоартериита: ветвей;

I тип - изолированное поражение дуги аорты и ее

II тип - нисходящая часть аорты (поражение грудного или брюшного отдела аорты и ее ветвей);

III тип - сочетанное поражение дуги аорты и ее ветвей с изменениями в грудном или брюшном отделах аорты;

IV тип - вовлекается легочная артерия, ее ветви, при этом возможно сочетание первых трех вариантов [2].

При всех формах гранулематозный воспалительный процесс начинается в адвентиции и наружных слоях медии, при микроскопическом исследовании гранулем обнаруживаются скопления лимфоцитов, плазматических, ретикулярных клеток. В дальнейшем наблюдается фиброз гранулем, пролиферация эндотелия, просвет сосуда суживается, создаются условия для развития тромбозов[3].

В описанном нами случае превалирующим является поражение левой ветви легочной артерии. Заболевания манифестировало болью в грудной клетке в виде «кома» в межлопаточном пространстве, затем присоединились боли в левой половине грудной клетки мигрирующего характера, периодически усиливающиеся, что было обусловлено прогрессированием воспалительного процесса в сосудистой стенке с повреждением эндотелия и образованием тромбов. Первопричиной сужения ветвей легочной артерии возможно послужил гранулематозный воспалительный процесс, встречающийся при аортоартериите, в дальнейшем создавались условия для развития хронической тромбоэмболии. При тромбоэмболии мелких ветвей легочной артерии болевой синдром возникает периодически, носит мигрирующий характер, может сопровождаться преходящей слабостью, кратковременной одышкой, что наблюдалось достаточно длительное время у больной Е. с тромбоцитозом, повышением уровней вч-СРБ, d-димеров.

Характерным проявлением поражения легочной артерии при неспецифическом аортоартериите IV типа является формирование признаков легочной гипертензии. Развитию легочной гипертензии предшествует постепенное сужение просвета мелких и средних сосудистых ветвей системы ЛА (капилляров, артериол) вследствие утолщения внутренней сосудистой оболочки - эндотелия. При тяжелой степени поражения легочной артерии возможна воспалительная деструкция мышечного слоя сосудистой стенки, повреждение стенок сосудов приводит к развитию хронического тромбоза и сосудистой облитерации. В нашем случае наряду с клиническими проявлениями заболевания настороженность специалистов вызвали прогрессирующая в течение последних 6 месяцев дилатация правых отделов сердца и легочная гипертензия.

Общими клиническими проявлениями данной патологии являются слабость, похудание, повышение температуры тела, сонливость, артралгии, миалгии [4]. У нашей больной были симптомы нарастающей слабости, усталости, снижение веса тела в течение последних четырех месяцев, артралгии.

Поражение нервной системы при неспецифическом аортоартериите обусловлено воспалительным процессом в области экстракраниальных артерий, преимущественно левой общей сонной артерии, ее внутренней ветви, правой общей сонной, а также позвоночной артерии. Больных беспокоят головные боли, головокружения, ухудшение памяти, внимания и работоспособности, пошатывание при ходьбе, часто бывают обморочные состояния. Появляется также объективная очаговая симптоматика, обусловленная ишемией соответствующего отдела ЦНС. У больной Е. поражение нервной системы проявлялось снижением работоспособности, внимания, ухудшением памяти, что было обусловлено диффузным утолщением стенок ОСА с гемодинамически незначимым стенозом ОСА (справа- 52\% и слева $53 \%$ ).

При поражении артерий, кровоснабжающих верхние конечности, появляется слабость и боли в руках, чувство онемения нарастающее при физической нагрузке, отсутствие пульса на лучевой, плечевой, подключичной артериях одной или обеих рук, холодные кисти. Иногда появляются боли в области левой половины грудной клетки, левого плеча, шеи. Характерны выраженная разница АД на руках, а также значительно более высокое АД на ногах, чем на руках. Пораженные артерии при пальпации болезненны, над ними выслушивается специфический шум [5]. У больной Е. подключичные артерии были без признаков стенозирования просвета, синдром «перемежающейся хромоты» верхних конечностей не был выражен, отмечалась некоторая слабость в руках и похолодание кистей, выявлена разница АД на 10 мм.рт.ст на руках, пульс слабого наполнения и напряжения, выслушивается шум в подключичной зоне слева.

При клинико-лабораторном обследовании больных неспецифическим аортоартериитом отмечаются умеренная анемия, лейкоцитоз, увеличение СОЭ, уменьшение уровня альбуминов, у-глобулинов, гаптоглобина, холестерина. Определение антигенов HLA выявляет иммунологические изменения крови: возможно повышение уровня иммуноглобулинов, в редких случаях обнаруживается ревматоидный фактор. У больной Е. в показателях крови имелись изменения характерные для воспалительного процесса (лейкоцитоз, нейтрофиллез, увеличение СОЭ, повышенный уровень вч-СРБ, тромбоцитоз, анемия).

В связи с многообразием клинических проявлений разработаны в 1990 году в американском колледже основные критерии диагноза неспецифического аортоартериита (болезнь Такаясу) [6]:

- Развитие симптомов в возрасте до 40 лет. 
- Слабость конечностей (слабость и боли в мышцах конечностей при движениях).

- Ослабление пульса на одной или обеих плечевых артериях. Разница артериального давления $>10$ мм рт. ст. на плечевых артериях.

- Шум на подключичных артериях или брюшной аорте.

- Изменения при ангиографии: сужение просвета или окклюзия аорты, ее крупных ветвей в проксимальных отделах верхних и нижних конечностей, не связанные с атеросклерозом, фибромускулярной дисплазией и др. (местные, сегментарные).

Для диагностики необходимо как минимум любые три из шести критериев. Наличие трех и более пунктов подтверждает диагноз неспецифического аортоартериита.

В приведенном нами клиническом случае начало заболевания в возрасте 36 лет, боль в грудной клетке в течение более 4-х лет, одышка, головокружение, слабость в руках, похолодание кистей., снижение пульсации на обеих плечевых артериях и разница систолического АД более 10 мм рт. ст., шум в проекции легочной артерии и надключичной области слева, рентгенологически выявленные фиброзные «поствоспалительные» изменения левого легкого более 1 года, развитие легочной гипертензии с дилатацией правых отделов сердца в последние 6 месяцев, характерные воспалительные изменения в крови и тромбоцитоз в течение 2-х лет, утолщение стенок нисходящей грудной аорты и левой ветви легочной артерии с признаками стенозирования просвета при КТ и МРТ исследованиях привели к диагностированию неспецифического аортоартерита с преимущественным поражением левой ветви легочной артерии нисходящего отдела грудной аорты, брахиоцефальных артерий [7].

\section{Выводы}

Разнообразие клинической картины болезни Такаясу приводит пациента к разным специалистам и на ранней стадии болезни почти не выявляется. Средний срок постановки диагноза неспецифического аортоартериита составляет 3 - 4 года, иногда и более. Именно редкость патологии становится одним из факторов, определяющих неузнаваемость, несвоевременность и неадекватность лечения и раннюю инвалидизацию больных. Особенностью описанного нами случая является преимущественное поражение левой ветви легочной артерии с развитием легочной гипертензии, которое встречается реже и достаточно скудно описано.

Диагностика неспецифического аортоартериита должна основываться на тщательном изучении жалоб и анамнеза заболевания, внимательном осмотре пациента с обязательным исследованием пульса на обеих лучевых артериях и на других сосудах, их аускультации, измерении артериального давления на обеих руках и ногах. Большое значение придается неинвазивным методам исследования (ультразвуковое дуплексное сканирование, компьютерная томография, магнитно-резонансная томография, позитронно-эмиссионная томография), которые позволяют установить диагноз на ранней стадии болезни, в период, когда имеется лишь утолщение сосудистой стенки.

Disclosures: There is no conflict of interest for all authors.

\section{Список использованной литературы}

1. Takayasu M. A case with peculiar changes of the retinal central vessels. Acta Ophthalm. Soc. Japan. 1908, 12:554-555.

2. Okorokov A.N. Diagnostika bolezney vnutrennikh organov (Diagnostics of internal organs diseases) [in Russian]. Moscow: Meditsinskaya literatura; 2007; 2: 25-28.

3. Lyskina G.A., Uspenskaya Ye.V. Klinicheskaya kartina, diagnostika i lecheniye nespetsificheskogo aortoarteriita u detey (Clinical pattern, diagnostics and treatment of non-specific aortoarteritis in children) [in Russian] Consilium Medicum Ukraina. 2008; 10:14-19.

4. Syvolap V.V., Kurilets L.O. Sluchay sindroma Takayasu v klinicheskoy praktike (A case of Takayasu syndrome in clinical practice) [in Russian]. Zaporozhskiy Meditsinskiy Zhurnal. 2014; 4(85): 90-94.

5. Savchenko V.A. Eponimicheskiye terminy v kardiologii (Eponymic terms in cardiology) [in Rusian]. Zaporozhskiy Meditsinskiy Zhurnal. 2015; 5(36):56-57.

6. Okorokov A.N. Diagnostika bolezney vnutrennikh organov (Diagnostics of internal organs diseases) [in Russian]. Moscow: Meditsinskaya literatura; 2007; 3: 347-376.

7. Belenkov Yu.N. Yezhemesyachnyy nauchno-prakticheskiy zhurnal. Kardiologiya. 2016; 9:56-58.

8. Rozendorff K. Osnovy kardiologii. Printsipy i praktika (Basics of cardiology. Principles and practice) [in Russian]. Moscow: Read Elsevier; 2010; 853-854.

How to cite this article: Saule Abseitova, Elmira Chuvakova, Timur Sarsengaliyev, Natalia Krivoruchko, Bagdad Abdizhami, Akmaral Moldazhanova. Nonspecific aortoarteritis with lesion of the pulmonary artery left branch (Takayasu's disease) [in Russian]. J Clin Med Kaz. 2018; 1(47):44-48 